\title{
Cervical-scapular muscles strength and severity of temporomandibular disorder in women with mechanical neck pain
}

\author{
Força dos músculos cérvico-escapulares e a severidade da disfunção \\ temporomandibular em mulheres com cervicalgia mecânica
}

\author{
Fernanda Pasinato ${ }^{[a]}$, Juliana Bordin ${ }^{[a]}$, Clarissa C. Santos-Couto-Paz ${ }^{[b]}$, Juliana Alves Souza ${ }^{[c]}$, \\ Eliane C. R. Corrêa ${ }^{[\mathrm{c}]^{*}}$ \\ [a] Universidade Federal do Pampa (Unipampa), Uruguaiana, RS, Brazil \\ [b] Universidade de Brasília (UnB), DF, Brazil \\ [c] Universidade Federal de Santa Maria (UFSM), Santa Maria, RS, Brazil
}

\begin{abstract}
Introduction: Changes in cervical muscle function have been observed in patients with neck pain (NP) and TMD. However, the relationship between TMD severity and neck muscle strength in the presence/absence of NP is unknown. Objective: To determine the prevalence of TMD in women with and without mechanical NP and assess the cervical-scapular muscle strength and its association with TMD severity. Methods: Fifteen volunteers without neck pain (CG) and 14 women with mechanical neck pain (NPG) took part and were selected by the Neck Disability Index. The diagnosis and severity of TMD were determined by the Research Diagnostic Criteria for TMD and Temporomandibular Index (TI), respectively. The strength of the upper trapezius muscle, and cervical flexor and extensor muscles was measured by digital hand dynamometer. Results: $64.5 \%$ of women with NP and 33.3\% without NP were diagnosed with TMD ( $\mathrm{p}=0.095)$. The NPG showed lower strength of the cervical flexor $(p=0.044)$ and extensor $(p=0.006)$ muscles, and higher TI $(p=0.038)$ than in the CG. It was
\end{abstract}

"FP: PhD, e-mail: fepas.fisio@yahoo.com.br JB: Grad, e-mail: ju.m.bordin@gmail.com CCSCP: PhD, e-mail: clarissacardoso@yahoo.com.br JAS: MSc, e-mail: fisioju@yahoo.com.br ECRC: PhD, e-mail: eliftrs@yahoo.com.br 
also verified moderate negative correlation between TI and the strength of dominant ( $p=0.046, r=-0.547$ ) and non-dominant $(\mathrm{p}=0.007, \mathrm{r}=-0.695)$ upper trapezius, and cervical flexors $(\mathrm{p}=0.023, \mathrm{r}=-0.606)$ in the NPG. Conclusion: There was no difference in the prevalence of TMD in women with and without NP. However, women with NP have lower cervical muscle strength - compared to those without NP - which was associated with greater severity of TMD. Thus, in women with NP associated with TMD, it is advisable to assess and address the severity of this dysfunction and identify the cervical-scapular muscles compromise.

Keywords: Temporomandibular Joint Disorders. Neck Pain. Muscle Strength Dynamometer. Muscle Strength.

\section{Resumo}

Introdução: Modificações da função muscular cervical têm sido verificadas em pacientes com cervicalgia e DTM. Entretanto, ainda não é conhecida a relação entre a severidade da DTM e a força muscular cervical na presença/ausência de cervicalgia. Objetivo: Verificar a prevalência de DTM em mulheres com e sem cervicalgia mecânica, avaliar a força dos músculos cérvico-escapulares e sua associação com a severidade da DTM. Métodos: Participaram 15 voluntárias sem dor cervical (GC) e 14 mulheres com cervicalgia mecânica (GCM), selecionadas por meio do Índice de Disfunção Relacionada ao Pescoço. O diagnóstico e a gravidade da DTM foram determinados pelos Critérios diagnósticos para pesquisa em desordens temporomandibulares e Índice Temporomandibular (IT), respectivamente. A força dos músculos trapézio superior, flexores e extensores cervicais foi aferida por dinamometria digital manual. Resultados: 64,5\% das mulheres com cervicalgia e 33,3\% das sem dor cervical apresentaram diagnóstico de DTM $(p=0,095)$. $O$ GCM apresentou menor força dos músculos flexores $(p=0,044)$ e extensores cervicais $(p=0,006)$ e maior IT $(p=0,038)$ que o GC. Também foi verificada correlação negativa moderada entre o IT e força dos músculos trapézio superior dominante ( $p=0,046$, $r=-0,547)$, não dominante ( $p=0,007, r=-0,695)$ eflexores cervicais ( $p=0,023, r=-0,606)$ no GCM. Conclusão: Não houve diferença na prevalência de DTM entre mulheres com e sem cervicalgia. Entretanto, mulheres com cervicalgia apresentaram menor força muscular cervical (comparadas às sem cervicalgia) que esteve associada a maior severidade da DTM. Assim, em mulheres com cervicalgia associada à DTM, é recomendável avaliar e abordar a severidade desta disfunção e o comprometimento dos músculos cérvico-escapulares.

Palavras-chave:Desordens da Articulação Temporomandibular. Cervicalgia. Dinamômetro de Força Muscular. Força Muscular.

\section{Introduction}

Mechanical neck pain is a non-specific disorder of the cervical spine, characterized by pain and discomfort exacerbated by neck movement, present in periods of remission and exacerbation (1). Cervical pain is the fourth leading cause of disability in adults, after lower back pain, depression and arthralgia (2). Epidemiologic studies estimate an annual prevalence of 30 to $50 \%$ in general population (3), and a systematic review reports the average frequency of $37.2 \%$ (4). Annually, $11.5 \%$ of economically active population experience some kind of limitation resulting from cervical pain (3), affecting the quality of life and causing significant socioeconomic impact (5).

It has been shown that individuals with chronic neck pain exhibit structural and functional changes including weakness and cervical flexor and extensor muscles imbalance (5-8), a decrease in the cervical range of motion, as well as proprioceptive deficits and compromise of postural control (9). Those changes are thought to be assigned to the reflex inhibition associated with pain, causing damage to the muscular function (10) and favoring the chronification of mechanical neck pain $(6,11)$. Although the biomechanical and neuroanatomic relationship between the cervical spine and the stomatognathic system has been verified in clinical and experimental studies (12-14), the link between the dysfunctions affecting these systems remains in dispute.

Cranio-cervical imbalance is associated with the coordinated action of anterior (masseter, suprahyoid, sternocleidomastoid, long muscle of head and neck) and posterior (trapezius, splenius, longissimus of head and neck) muscle chains, linked by muscularaponeurotic structures transmitting to each other 
imbalances and tensions (15). Furthermore, the sternocleidomastoid muscle (SCM) acts as a synergist in the support and stabilization of the head and the cervical region. Its coactivation during teeth clenching varies from 3 to $10 \%$ of the maximal voluntary contraction (16), suggesting a functional relationship between the stomatognathic and cervical systems. Thus, compensations between these systems may be a necessary mechanism for achieving stability and efficiency during the masticatory function $(17,18)$.

In addition to the biomechanical relationship, evidence exists $(19,20)$ that cervical and stomatognathic systems interact mutually in the nociceptive and proprioceptive domains. The association between orofacial and cranio-cervical symptoms can be explained by the convergence of second-order nociceptive neurons, which receive cervical and trigeminal afferents in the brainstem sensory nuclear complex. So, nociception resulting from a cervical dysfunction may increase the central sensitization of the trigeminal central nucleus, leading to diffusion of pain to the craniofacial area and vice versa $(11,21)$.

Temporomandibular disorder is a generic term referring to painful and/or dysfunctional conditions of the mastication muscles, temporomandibular joints and structures related, with the cervical spine among them (22). A comorbity between neck pain and TMD has been observed $(23,24)$, and there is evidence that TMD might be related to the decrease in cervical muscles resistance $(11,25)$. However, the role of TMD severity, as well as its association with the isometric strength of cervicalscapular muscles, in the presence and/or absence of neck pain, has not been described in the literature.

Furthermore, a few research addressed the classification of TMD regarding its severity. The Temporomandibular Index (26) allows for this classification, as provides scores regarding the clinical aspects relevant for the diagnosis of TMD such as: limitation of mandibular movement range, muscle and joint pain, as well as the presence of joint noise. Clinically, the utilization of this index makes possible the determination of the dysfunction severity (14) and the verification of therapeutic interventions results (27).

Therapeutic approaches, targeted to the craniocervical-mandibular functional unit, have been recommended for patients with primary dysfunctions, both in the cervical spine and the stomatognathic system $(27,28)$. Additional studies are required, however, that analyze the relationship among the changes in these systems.
The purpose of this study is to provide information to help understand the details about the interaction between the cervical spine and the temporomandibular joint (TMJ), taking into account the role of TMD severity and the cervical-scapular muscles strength. This knowledge will be able to guide clinical practice in a more objective way, thus contributing for the decision-making regarding the assessment and the elaboration of therapeutic strategies.

Based on the aforementioned, the present study purpose is to investigate the prevalence of TMD in women with and without mechanical neck pain, as well as the assessment of cervical-scapular muscles strength and their association with TMD severity in these individuals.

\section{Methods}

\section{Research characterization and the participants}

The present research was approved by the Ethics Committee of the Federal University of Pampa, Uruguaiana, RS (protocol number 0112011) comprising an observational study, cross-sectional in design. The volunteers were recruited in the municipality of Uruguaiana, among those who responded to the divulgation of this research through printed and electronic media. Fifteen women presenting with mechanical neck pain paired with 15 women without neck pain were selected by convenience. However, one volunteer with neck pain who has not completed the assessment was excluded.

Therefore, twenty-nine women, aged 21 to 42, were assessed and allocated in two groups according to the neck disability index (NDI) results $(29,30)$ : NPG - Mechanical Neck Pain Group ( $\mathrm{n}=14)$, comprising women with neck pain complaint for more than three months (5) and cervical disability confirmed by the NDI score > 4; CG - Control Group ( $n=15)$, comprising volunteers without neck pain complaint, with NDI score $\leq 4$.

Research exclusion criteria were: history of trauma, fractures and surgery in the area assessed, diagnosis of cervical radiculopathy or myelopathy, fibromyalgia and inflammatory joint diseases. Moreover, the participants could not have exercised to strengthen the upper limbs and neck muscles in the last six months. All volunteers were informed about 
the study objectives and had a free and informed consent signed.

\section{Assessment Procedures}

Disability related to neck pain was assessed through the Neck Disability Index. This is a questionnaire translated and validated for the Brazilian population (29) comprising 10 items regarding the interference of pain while performing daily activities, except for item 5, which assesses headache intensity. The alternatives are numbered from 0 to 5 , describing increasing degrees of neck pain interference on the activity assessed. The score consists of the sum of scores in each of the 10 items, ranging from 0-50 points. The individual is rated as mild disability from 5 to 14 points; moderate disability, from 15 to 24 points; severe disability, from 25 to 34 points; and complete disability ranging from 35 to 50 points (30).

The diagnosis of TMD was made through clinical exam, according to the protocol established by the research diagnostic criteria for temporomandibular disorders (RDC/TMD) (31), performed by a previously trained examiner. The algorithms of the instrument were employed to establish the diagnosis and TMD classification (myofascial, disc or joint disorder).

From the results of RDC, scores were calculated for the Temporomandibular Index (TI) (26). TI comprises three sub-indices: functional index (FI), muscle index (MI) and joint index (JI). Each sub-index value is calculated by adding the scores of the items assessed, divided by the total number of items. TI consists of the mean value of the three sub-indices, ranging from 0 to 1 , with the highest possible punctuation being 1 , denoting higher severity of dysfunction. FI includes 12 items regarding the amplitude of mandibular movement, characterizing pain or limitation and deviations during mouth opening movement. MI measures the pain related to bilateral digital palpation of the intra and extra-oral masticatory muscles, in a total of 20 sites. JI assesses the pain evoked by digital palpation of the lateral pole and posterior ligament, and the occurrence of noise in each TMJ.

The isometric strength of cervical-scapular muscles was assessed by digital hand dynamometer Microfet 2 HHD (Hoogan Health Industries, West Jordan, UT, USA). The assessment protocol of muscle strength was based on studies by Cools et al. (32), and Cagnie et al. (6). The examiners were previously trained by a researcher with previous experience in the application of the assessment protocol of muscle strength, and the required care was taken regarding the specificity of the muscle function assessed. Before muscle strength measurement, the volunteers' body mass was registered for subsequent data normalization, as described by Cools et al. (32).

The assessment of upper trapezius muscle was performed with the volunteer in a sitting position. The dynamometer was placed on the upper scapular region, and resistance was applied over scapular depression, while asking the scapula elevation (32) (Figure 1a). The extensor muscles strength was assessed with the volunteer positioned on a stretcher in dorsal decubitus, with the dynamometer positioned below the occipital region, and the volunteer was asked to make maximum effort to perform cervical extension against the dynamometer (Figure 1b). The cervical flexor muscles were assessed with the participant in ventral decubitus and the dynamometer placed under the frontal bone. At this point, the volunteer was asked to flex the cervical spine against the dynamometer resistance (Figure 1c). In both tests, the dynamometer was positioned so that the cervical spine remained in neutral position and, in the meantime, the participant was asked to keep the distance between the mento and stern to avoid craniocervical motion during the measurement process. In order to control the utilization of the trunk muscles, a safety belt was placed on the volunteer's shoulder, maintaining the trunk fixed during the test.

Each muscle was assessed bilaterally, repeating twice. The isometric contraction was kept for 6 seconds and the volunteers were encouraged to employ maximum strength during the test by means of voice command, "push, push, push". Each registration was followed by a one-minute resting interval. Data collection was performed in the same sequence for all the volunteers and by the same examiner.

The averages were calculated for both measures, which were expressed in kilogram-force (Kgf) and normalized by each volunteer's body mass (Kg) (each muscle strength value/body mass) (32). The normalization of strength data is fundamental to allow the comparison of individuals of different physical completions.

Inter and intra-examiner reliability of measurements of cervical muscles strength in dorsal and ventral decubitus, performed with a digital hand dynamometer, were previously assessed in a group of healthy individuals, showing excellent levels of reproducibility and reliability (ICC >0.9) (33). 


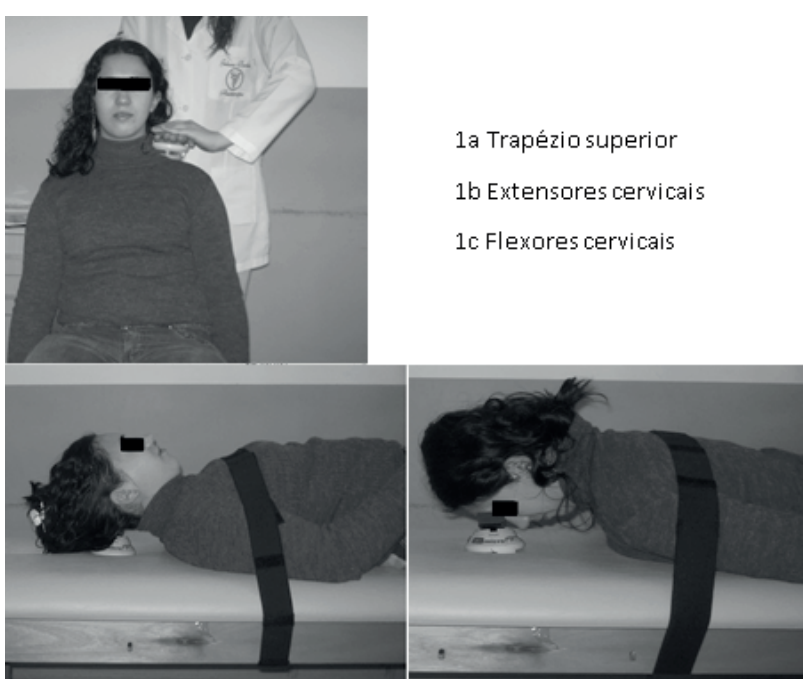

Figure 1 - Volunteer positioning during assessment of isometric strength of upper trapezius (1a); cervical extensor (1b) and cervical flexor (1c) muscles

\section{Statistical Analysis}

After data collection, a descriptive analysis of the participants' clinical-demographic data was performed. Next, the Kolmogorov-Smirnov test was used for analyzing the normality of data regarding the primary outcome variables, and the Chi-square test to compare the frequency of TMD diagnosis between the groups. A comparison between the measurements of cervical-scapular muscle strength was performed by the Mann Whitney test, and the TI values were compared by t-test, according to the test for normality of variables. The strength results for each muscle were normalized by each individual body mass and expressed in terms of average and standard deviation. For analyzing the correlation between data regarding cervical-scapular muscles strength and TI, the Spearman correlation was used. The correlation was considered strong for correlation coefficient values $(\mathrm{r}) \geq 0.7$; moderate when 0.3 $<\mathrm{r}<0.7$, and weak when $\mathrm{r}$ was $\leq 0.3$. With all the tests a significance level of $\alpha<0.05$ was considered. For statistical data analysis, the Statsoft STATISTICA $7.1^{\circledR}$ software was used.

\section{Results}

Fourteen women with mechanical neck pain (NP) and 15 women without neck pain (CG) took part in this study. Among women with NP, 9 showed mild disability, and 5 showed moderate disability.

The results of descriptive statistics regarding the clinical-demographic characteristics - age, weight, the neck disability index (NDI) scoring and the temporomandibular index (TI) - are shown in table 1 . The groups did not differ regarding body weight. As for NDI and TI scores, significantly higher values in NPG than those in CG were observed.

Table 1- Clinical-demographic characteristics of participants in control group and neck pain group

\begin{tabular}{lcccc}
\hline & Group & Average (SD) & Cl 95\% & Value p \\
\hline \multirow{2}{*}{ Age (years) } & NPG & $27.5 \pm 3.89$ & $25.26-29.74$ & 0.050 \\
& CG & $25.4 \pm 6.04$ & $22.05-28.76$ & \\
Weight (Kg) & NPG & $62.93 \pm 14.03$ & $54.83-71.03$ & 0.188 \\
& CG & $58.13 \pm 12.37$ & $51.28-64.98$ & \\
NDI (points) & NPG & $11.43 \pm 5.12$ & $8.47-14.39$ & $0.000^{*}$ \\
TI (points) & CG & $1.67 \pm 1.37$ & $0.71-2.6$ & \\
& NPG & $0.393 \pm 0.22$ & $0.26-0.52$ & $0.038^{*}$ \\
\hline
\end{tabular}

Note: NDI, Neck disability index; TI, temporomandibular index; NPG, Mechanical Neck Pain Group; CG, Control Group; *significantly different, a = 0.05 
The frequency of TMD diagnosis in women with mechanical neck pain was $64.26 \%$, while in the control group it was $33.33 \%$. This percentage difference has not achieved a statistical significance level according to Chi-square test $\left(\mathrm{X}^{2}=2.778, \mathrm{p}=0.095\right)$.

The volunteers' distribution according to the diagnostic classification of TMD by RDC/TMD is described in Table 2.

Table 2 - Diagnostic classification of TMD for control group (CG) and mechanical neck pain group (NPG)

\begin{tabular}{|c|c|c|}
\hline Diagnoses of DTM & $\begin{array}{c}\text { NPG } \\
(n=14)\end{array}$ & $\begin{array}{c}C G \\
(n=15)\end{array}$ \\
\hline la (Myofascial pain) & 1 & 2 \\
\hline $\begin{array}{l}\text { Ila (Disc displacement with } \\
\text { reduction) }\end{array}$ & 0 & 1 \\
\hline IIla (Arthralgia) & 1 & 0 \\
\hline la, Ila & 0 & 1 \\
\hline la, IIla & 2 & 0 \\
\hline Ib, IIla & 4 & 0 \\
\hline Ila, IIla & 1 & 1 \\
\hline Without diagnosis & 5 & 10 \\
\hline Multiple diagnoses $(>3$ ) & 7 & 0 \\
\hline
\end{tabular}

Note: NPG showed lower isometric muscle strength of cervical flexor $(p=0.044)$ and extensor $(p=0.006)$ muscles than CG (Figure 2$)$

From the analysis of figure 3 , it can be observed that in NPG, TI scores showed a moderate negative correlation $(0.3<\mathrm{r}<0.7)$, with strength values assessed for every muscle, except for the cervical extensors. In CG no significant correlation was found.

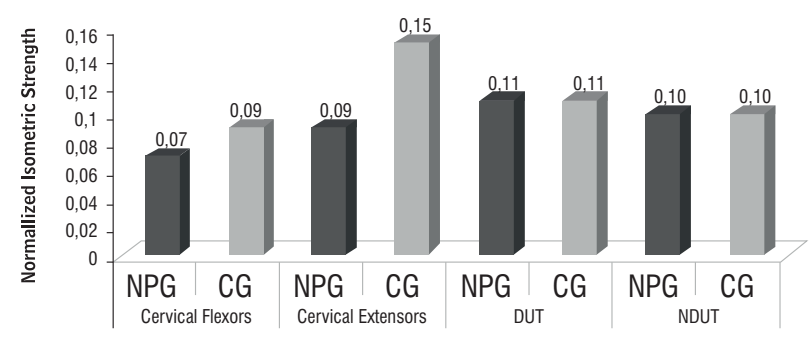

Figure 2 - Comparison between normalized isometric strength of cervical-scapular muscles in patients with and without neck pain
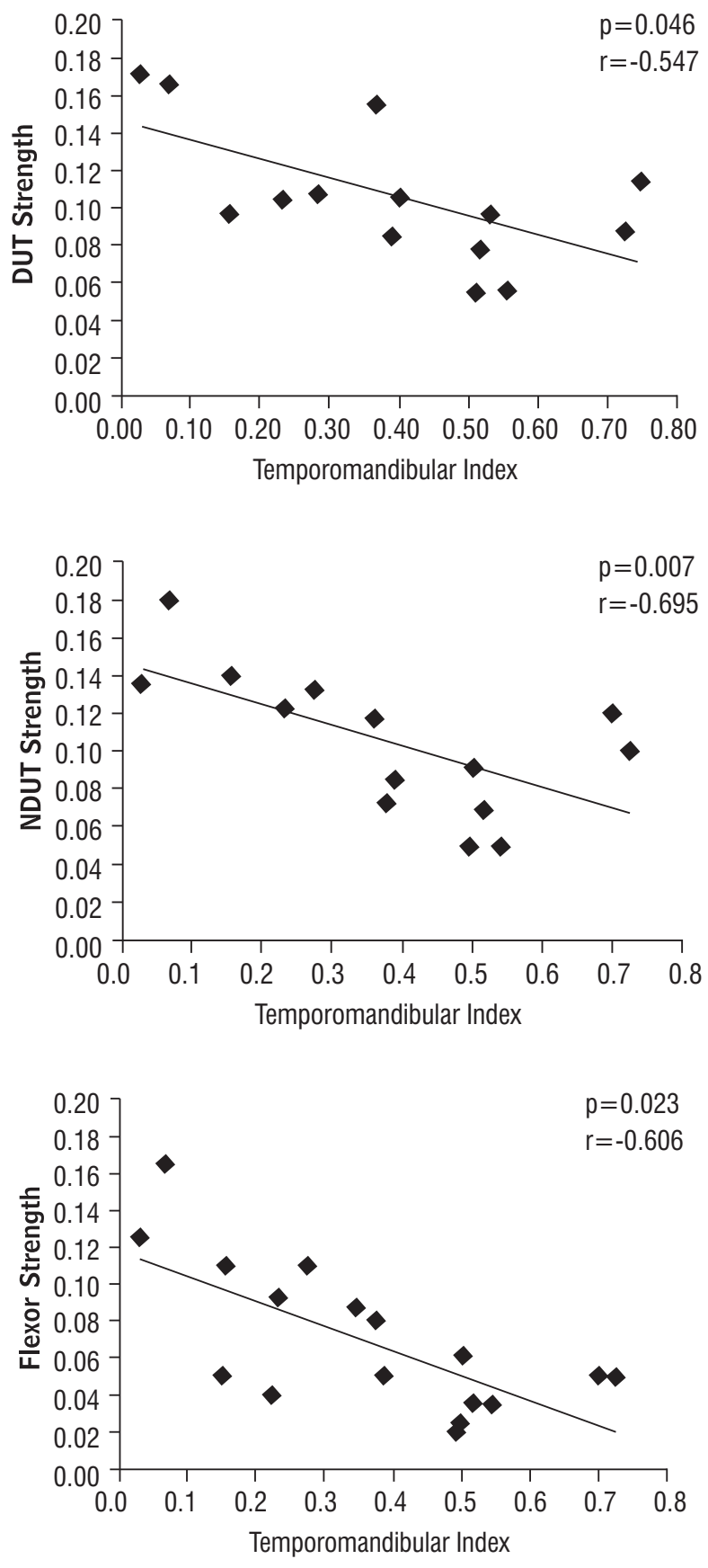


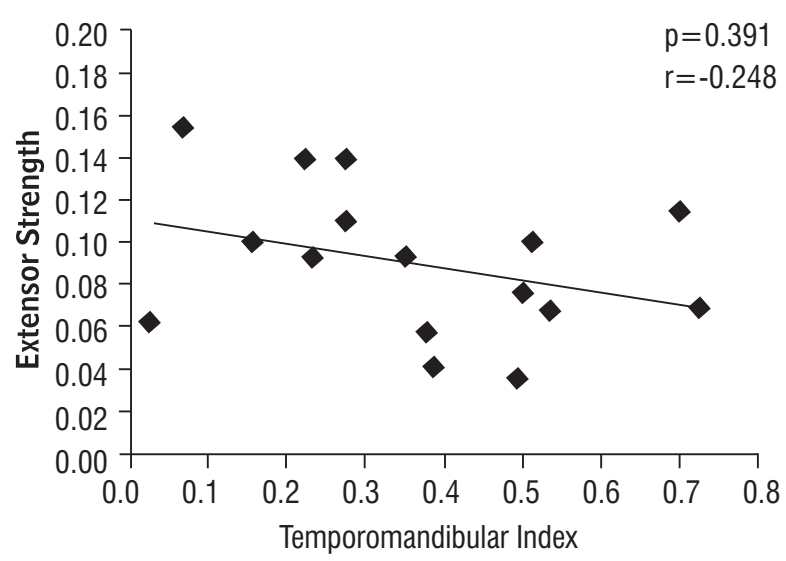

Figure 3 - Dispersion graph and description of correlation values between the severity of TMD (Temporomandibular Index) and normalized isometric strength of dominant upper trapezius (DUT), non-dominant upper trapezius (NDUT), cervical extensor, and flexor muscles in women with neck pain

\section{Discussion}

The main findings of this study show that women with neck pain present lower strength of cervical muscles and greater TMD severity compared with women without neck pain. Additionally, in the presence of neck pain, greater TMD severity was related to lower strength of cervical-scapular muscles.

Although the prevalence of TMD diagnosis in women with and without neck pain is not statistically different (64.3\% versus $33.3 \%$, respectively), the analysis of TI revealed a difference between the groups regarding the degree of involvement caused by TMD, which was more severe in NPG. These findings are consistent with the fact that $50 \%$ of women with neck pain present with multiple simultaneous diagnoses of TMD ( $>3$, with the association between myofascial pain and arthralgia being the most frequent disorders), while in CG this was not verified.

Previously, Vicsher et al. (34) showed that the frequency of signals and symptoms of TMD in individuals with cervical spine disorders are comparable to those found in the adult population without any disorder. In contrast, Feirão et al. (35) verified the presence of TMD in $90 \%$ of patients with neck pain receiving physical therapy treatment. In the present study, the volunteers were selected in the community and were not receiving treatment for their dysfunction. These factors might have been decisive for the differences among the prevalence found. Regarding the CG, the frequency described in the present study shows values similar to those described for the general population regarding signals and symptoms of TDM (37.5\%) (22).

According to the literature, individuals with mechanical neck pain present with hyperalgesia in the trigeminal region, and lower levels of pain sensitivity to the pressure of masseter and temporal muscles (36), the reduction of which is associated with the intensity and duration of symptoms in the cervical region. Thus, the chronicity of neck pain may potentialize the trigeminal sensitization, favoring pain triggering and a dysfunction of the stomatognathic system, which in this study was confirmed by the greater severity of TMD found in NPG. This result denotes how important is the utilization of indices or scales that quantify TMD severity (14), as they are able to identify subtle changes, even in the absence of a diagnosis for this dysfunction. Moreover, TI allows for the characterization and definition of the component that contributes the most for TMD severity - muscular, articular or functional - favoring the selection of strategies and specific therapeutic interventions in the stomatognathic system, and monitoring the progress of therapeutic outcomes.

Women with NP showed lower values for isometric strength of cervical flexor and extensor muscles, compared to CG, with greater reduction for extensor muscles. Changes in cranio-cervical strength and motor control in the context of neck pain have been described in the literature $(1,7,8,12,13,37,38)$, and they are linked to an increase in disability levels caused by chronic neck pain (7). These modifications, including a reduction in muscle strength, may be explained by the mechanism of neural inhibition caused by pain (10) and by the change in motor strategies related to cervical spine control and stability while executing the task (38).

The investigation of the presence of $\operatorname{TMD}(34,35)$ and the analysis of muscle strength in the context of neck pain $(4,6-8,10,12)$ have been performed. Additionally, this research results show the moderate negative correlation between the TI (indicating DTM severity) and the isometric strength of cervical flexor, dominant upper trapezius and non-dominant upper trapezius muscles in NPG. The same correlation was not observed in CG, which results may have been influenced by the smaller number of volunteers with the diagnosis of TMD in this group.

Therefore, the reduction of cervical-scapular muscle strength can be explained in part by the increase in 
the severity of TMD in women with neck pain and vice versa. Specifically, lower muscle strength of cervical flexors, associated with higher severity of TMD, can be understood as an extension of functional damage to SCM muscle, present in cases of TMD. Previous evidence (16, 17) confirmed the role of muscle SCM - a primary cervical spine flexor - as a synergist in the stabilization of the head during the mastication function, as well as the changes in its electromyographic activity in the presence of $\operatorname{TMD}(7,39,40)$. In addition, the posture control of the head and cervical spine is directly related to the stability promoted by an adequate synergism, the muscle ability to generate strength and the resistance of agonist and antagonist cervical muscles $(14,15)$. Considering that the mandible is a mobile bone with articulation with the skull by means of TMJ, the effective control of mandibular functions depends on a stable cervical base (17). Thus, the worst performance in the test of cervical flexion strength can also be related to the functional compensations required for the maintenance of the masticatory system stability and efficiency $(17,18)$.

Other factors that may be associated to the lowest recruitment and capacity of torque generation during cervical function (25) are the electromiographic hyperactivity at rest and the hyperalgesia of SCM and upper trapezius muscles commonly observed in individuals with myogenic TMD $(17,40-42)$. Thus, the inhibition of the muscle mechanism may be contributing to the poorer performance in the generation of cervical flexion strength in more severe case of TMD associated with neck pain.

The reduction in the maintenance time of contraction and the resistance of cervical flexor and extensor muscles in individuals with TMD associated with cervical dysfunction was previously demonstrated $(11,25)$. In contrast, Armijo-Olivo et al. (43) did not find differences between maximal strength of cervical flexor muscles in individuals with TMD and asymptomatic individuals, or a correlation between mandibular impairment and muscle strength. In these studies, TMD severity was not assessed, and the authors (44) hypothesized that different conditions in the registration of strength and/or a sample of patients with greater severity of TMD might influence the results. Further investigation is needed to clarify the role of this function in the modification of maximal strength of the cervical musculature.

Despite the significant correlations found in this study, the limited number of subjects assessed does not allow the generalization of results, and they should be analyzed with caution. The results presented cannot identify the individual contribution of TMD to the damages in the generation of cervical-scapular muscles strength in women with neck pain, since these variables were not analyzed in a control group of healthy women. Thus, further research is suggested comparing individuals with and without TMD in order to better define the implications of this dysfunction for the decrease of muscle strength and neck pain.

In view of this study results, professionals must be aware that signals and symptoms in the cervical and mandibular area cannot be considered alone. The determination of TMD severity in women with neck pain, as well as the assessment of cervical-scapular muscles strength may help determine the actions necessary to reduce the disability, and plan effective interventions for the treatment of both dysfunctions.

\section{Conclusion}

No differences were observed in the prevalence of TMD in women with and without neck pain. Women with neck pain, however, presented lower strength of cervical flexor and extensor muscles and greater severity of TMD compared with those without neck pain. Moreover, this study showed that the increase of TMD severity is related to a decrease in the strength of cervical flexor and upper trapezius muscles in women with neck pain. The presence of this association reinforces the importance of the assessment of TMD severity and the strength of cervical-scapular muscles in women with neck pain. Such information can contribute for the elaboration of effective therapeutic strategies for the treatment of these disorders.

\section{References}

1. O'Leary S, Falla D, Jull G. The relationship between superficial muscle activity during the cranio-cervical flexion test and clinical features in patients with chronic neck pain. Man Ther. 2011; 16(5):452-5.

2. Cohen SP. Epidemiology, diagnosis, and treatment of neck pain. Mayo Clin Proc. 2015; 90(2):284-99.

3. Hogg-Johnson S, Van der Velde G, Carroll LJ, Holm LW, Cassidy JD, Guzman J, et al. The burden and determinants of neck pain in the general population: results of the Bone and Joint Decade 2000-2010 Task Force on Neck Pain and Its Associated Disorders. J Manip Physiol Ther. 2009; 32(2 Suppl):S46-60. 
4. Fejer R, Kyvik KO, Hartvigsen J. The prevalence of neck pain in the world population: a systematic critical review of the literature. Eur Spine J. 2006; 15(6):834-48.

5. Salo PK, Hakkinen AH, Kautiainen H, Ylinen JJ. Effect of neck strength training on health-related quality of life in females with chronic neck pain: a randomized controlled 1-year follow-up study. Health Qual Life Outcomes. 2010; 8:48.

6. Cagnie B, Cools A, De Loose V, Cambier D, Danneels L. Differences in isometric neck muscle strength between healthy controls and women with chronic neck pain: the use of a reliable measurement. Arch Phys Med Rehabil. 2007; 88(11):1441-5.

7. Lindstrom R, Schomacher J, Farina D, Rechter L, Falla D. Association between neck muscle coactivation, pain, and strength in women with neck pain. Man Ther. 2011; 16(1):80-6.

8. Lindstroem R, Graven-Nielsen T, Falla D. Current pain and fear of pain contribute to reduced maximum voluntary contraction of neck muscles in patients with chronic neck pain. Arch Phys Med Rehabil. 2012; 93(11):2042-8.

9. Jørgensen R, Ris I, Falla D, Juul-Kristensen B. Reliability, construct and discriminative validity of clinical testing in subjects with and without chronic neck pain. BMC Musculoskelet Disord. 2014;15:408.

10. Ylinen J, Takala EP, Kautiainen H, Nykanen M, Hakkinen A, Pohjolainen T, et al. Association of neck pain, disability and neck pain during maximal effort with neck muscle strength and range of movement in women with chronic non-specific neck pain. Eur J Pain. 2004; 8(5):473-8.

11. Armijo-Olivo S, Fuentes JP, Da Costa BR, Major PW, Warren S, Thie NM, et al. Reduced endurance of the cervical flexor muscles in patients with concurrent temporomandibular disorders and neck disability. Man Ther. 2010; 15(6):586-92.

12. Falla D, Farina D. Neuromuscular adaptation in experimental and clinical neck pain. J Electromyogr Kinesiol. 2008; 18(2):255-61.

13. Ballenberger N, Von Piekartz H, Paris-Alemany A, La Touche R, Angulo-Diaz-Parreno S. Influence of different upper cervical positions on electromyography activity of the masticatory muscles. J Manip Physiol Ther. 2012; 35(4):308-18.
14. Milanesi JM, Weber P, Pasinato F, Corrêa ECR. Severidade da desordem temporomandibular e sua relação com medidas cefalométricas craniocervicais. Fisioter Mov. 2013; 26(1):79-86.

15. Corrêa EDR, Bérzin F. Temporomandibular disorder and dysfunctional breathing. Braz J Oral Sci. 2004; 3(10):498-502.

16. Giannakopoulos NN, Hellmann D, Schmitter M, Krüger B, Hauser Thomas, Schindler HJ. Neuromuscular interaction of jaw and neck muscles during jaw clenching. J Orofac Pain. 2013; 27(1):61-71.

17. Chandu A, Suvinen TI, Reade PC, Borromeo GL. Electromyographic activity of frontalis and sternocleidomastoid muscles in patients with temporomandibular disorders. J Oral Rehabil. 2005; 32(8):571-6.

18. Strini PJ, Strini PJ, Barbosa TS, Gavião MB. Assessment of thickness and function of masticatory and cervical muscles in adults with and without temporomandibular disorders. Arch Oral Biol. 2013; 58(9):1100-8.

19. Svensson P, Wang K, Sessle BJ, Arendt-Nielsen L. Associations between pain and neuromuscular activity in the human jaw and neck muscles. Pain. 2004; 109(3):225-32.

20. Kobayashi M, Yabushita T, Zeredo JL, Toda K, Soma K. Splenius muscle activities induced by temporomandibular jointstimulation in rats. Brain Res Bull. 2007; 72(1):44-8.

21. De-la-Llave-Rincon AI, Alonso-Blanco C, Gil-Crujera A, Ambite-Quesada S, Svensson P, Fernandez-deLas-Penas C. Myofascial trigger points in the masticatory muscles in patients with and without chronic mechanical neck pain. J Manip Physiol Ther. 2012; 35(9):678-84.

22. Carrara SV, Conti PCR, Barbosa JS. Termo do $1^{\circ}$ Consenso em Disfunção Temporomandibular e Dor Orofacial. Dental Press J Orthod. 2010; 15(3):114-20.

23. Wiesinger B, Malker H, Englund E, Wanman A. Does a dose-response relation exist between spinal pain and temporomandibular disorders? BMC Musculoskelet Disord. 2009;10:28.

24. Visscher CM, Ligthart L, Schuller AA, Lobbezoo F, De Jongh A, Van Houtem CM, Boomsma DI. Comorbid disorders and sociodemographic variables in temporomandibular pain in the general Dutch population. J Oral Facial Pain Headache. 2015; 29(1):51-9. 
25. Armijo-Olivo S, Silvestre RA, Fuentes JP, Da Costa BR, Major PW, Warren S, et al. Patients with temporomandibular disorders have increased fatigability of the cervical extensor muscles. Clin J Pain. 2012; 28(1):55-64.

26. Pehling J, Schiffman E, Look J, Shaefer J, Lenton P, Fricton J. Interexaminer reliability and clinical validity of the temporomandibular index: a new outcome measure for temporomandibular disorders. J Orofac Pain. 2002; 16(4):296-304.

27. Freire AB, De Nardi AT, Boufleur J, Chiodelli L, Pasinato F, Corrêa ECR. Abordagem fisioterapêutica multimodal: efeitos sobre o diagnóstico e a gravidade da disfunção temporomandibular. Fisioter Mov. 2014; 27(2):219-27.

28. La Touche R, Fernández-de-las-Penas C, FernándezCarnero J, Escalante K, Angulo-Diaz-Parreno S, Paris-Alemany A, et al. The effects of manual therapy and exercise directed at the cervical spine on pain and pressure pain sensitivity in patients with myofascial temporomandibular disorders. J Oral Rehabil. 2009; 36(9):644-52.

29. Cook C, Richardson JK, Braga L, Menezes A, Soler X, Kume $\mathrm{P}$, et al. Cross-cultural adaptation and validation of the Brazilian Portuguese version of the Neck Disability Index and Neck Pain and Disability Scale. Spine. 2006; 31(14):1621-7.

30. Vernon H. The Neck Disability Index: state-of-theart, 1991-2008. J Manipulative Physiol Ther. 2008; 31(7):491-502.

31. Dworkin SF, Le Resche L. Research diagnostic criteria for temporomandibular disorders: review, criteria, examinations and specifications, critique. J Craniomandib Disord. 1992; 6(4):301-55.

32. Cools AM, Johansson FR, Cambier DC, Velde AV, Palmans T, Witvrouw EE. Descriptive profile of scapulothoracic position, strength and flexibility variables in adolescent elite tennis players. Br J Sports Med. 2010; 44(9):678-84.

33. Cassafuz TI, Delavati VK. Confiabilidade da medida da força dos músculos flexores e extensores cervicais por meio da dinamometria manual digital [TCC]. Uruguaiana: Universidade Federal do Pampa; 2013.

34. De Wijer A, Steenks MH, Bosman F, Helders PJM, Faber J. Symptoms of the stomatognathic system in temporomandibular and cervical spine disorders. J Oral Rehabil. 1996; 23(11) :733- 41.
35. Ferão MIB, Traebert, J. Prevalence of temporomandibular dysfunction in patients with cervical pain under physiotherapy treatment. Fisioter Mov. 2008; 21(4):63-70.

36. La Touche R, Fernández-de-Las-Penas C, FernándezCarnero J, Díaz-Parreno S, Paris-Alemany A, ArendtNielsen L. Bilateral mechanical-pain sensitivity over the trigeminal region in patients with chronic mechanical neck pain. Journal Pain. 2010; 11(3):256-63.

37. Boudreau SA, Falla D. Chronic neck pain alters muscle activation patterns to sudden movements. Exp Brain Res. 2014; 232(6):2011-20.

38. Schomacher J, Falla D. Function and structure of the deep cervical extensor muscles in patients with neck pain. Man Ther. 2013; 18(5):360-6.

39. Ries LGK, Alves MC, Bérzin F. Asymmetric activation of temporalis, masseter, and sternocleidomastoid muscles in temporomandibular disorder patients. Cranio. 2008; 26(1):59-64.

40. Pallegama RW, Ranasinghe AW, Weerasinghe VS, Sitheeque MA. Influence of masticatory muscle pain on electromyographic activities of cervical muscles in patients with myogenous temporomandibular disorders. J Oral Rehabil. 2004; 31(5):423-9.

41. Milanesi JM, Corrêa ECR, Borin GS, Souza JA, Pasinato F. Atividade elétrica dos músculos cervicais e amplitude de movimento da coluna cervical em indivíduos com e sem DTM. Revista Fisioterapia e Pesquisa. 2011; 18(4):317-22.

42. Silveira A, Armijo-Olivo S, Gadotti IC, Magee D. Masticatory and cervical muscle tenderness and pain sensitivity in a remote area in subjects with a temporomandibular disorder and neck disability. J Oral Facial Pain Headache. 2014; 28(2):138-46.

43. Armijo-Olivo SL, Fuentes JP, Major PW, Warren S, Thie $\mathrm{NM}$, Magee DJ. Is maximal strength of the cervical flexor muscles reduced in patients with temporomandibular disorders? Arch Phys Med Rehabil. 2010; 91(8):1236-42.

44. Armijo-Olivo SL, Magee DJ. Cervical musculoskeletal impairments and temporomandibular disorders. J Oral Maxillofac Res. 2012; 3(4):1-18.

Received: $12 / 16 / 2013$ Recebido: 16/12/2013

Approved: 09/03/2015 Aprovado: 03/09/2015 